\title{
UJI UNJUK KERJA ALAT PENGOLAH TEPUNG PISANG DI KECAMATAN LOA KULU
}

\begin{abstract}
Oleh :
Sulharman *

ABSTRACT

East Kalimantan has abundant potencies of horticultural comodity of banana. The production of banana is about 25,216 ton / year harvested from the area of 4,784 hectares (Dinas Pertanian Tanaman Pangan Propinsi Kaltim, 2002). Mostly the banana variety is pisang kepok (Musa Acuminax Balbisiana Colla) that in certain stadium can produce high carbohydrate and it is used as raw material of flour for cake and infant food industries. Currently there is a set of machines to make banana flour in agribussines sub terminal in the residance of Loa Kulu of Kutai Kertanegara Regency. To know exactly the machines performances, it is needed to conduct a performance test to every machine involved. The tests conducted in Loa Kulu showed that the actual capacity of slicing in avarage is $177 \mathrm{~kg} /$ hour with the thickness avarage of $2 \mathrm{~mm}$ and the efficiency of the slicer is $27,7 \%$ on the other hand, the strainer capacity is about $1,75-\mathrm{kg} /$ minute or in avarage $2,52 \mathrm{~kg} /$ minute. It has an avarage rendemen of $79 \%$ and lost in process of $2,81 \%$ more over, the dryer capacity is $11,39 \mathrm{~kg}$ / hour and it also has rendemen and lost in process of $24,84 \%$ and $4,79 \%$ respectively. In additioan, by using a system of heat exchanger the efficiency of dryer becomes $20,49 \%$. Finally the disk mills making has a rendemen $87,80 \%$ and lost in process of $2,56 \%$.
\end{abstract}

Keywords : Banana flour,slicer,strainer machine, dryer, the disk mills

\section{PENDAHULUAN}

Kalimantan Timur memiliki potensi pisang yang merupakan komoditi hortikultura yang potensinya cukup besar dengan produksi 25.216 ton/tahun dengan luas areal $4.784 \mathrm{Ha}$ ( Dinas Pertanian Tanaman Pangan Prop. Kaltim 2002).

Sebagian besar pisang adalah jenis pisang kepok (Musa Acuminax Balbisiana Colla) yang pada stadium tertentu dapat menghasilkan karbohidrat yang tinggi sebagai bahan baku tepung untuk industri kue dan makanan bayi.

Saat ini sudah terdapat mesin pembuat tepung pisang yang berada di sub terminal agribisnis di kecamatan Loa Kulu kabupaten Kutai Kertanegara. Untuk mengetahui secara pasti unjuk kerja alat penepung pisang yang ada, maka perlu diadakan uji unjuk kerja masing-masing alat penepung tersebut secara pasti.

Tujuan dari penelitian ini adalah untuk menghitung unjuk kerja alat penepung pisang yang ada di kecamatan Loa Kulu kabupaten Kutai Kerta negara.

Harapan dari pengujian ini adalah untuk mendapatkan secara pasti unjuk kerja alat penepung pisang yang ada di kecamatan Loa Kulu kubapaten Kutai Kertanegara.

\section{BAHAN DAN PERALATAN}

Bahan yang dibutuhkan untuk penelitian ini adalah pisang, air, minyak tanah, plastik pengemas, dan bahan untuk analisa. 
Sedangkan alat - alat yang digunakan dalam penelitian ini adalah pisau, baskom plastik, timbangan spring balance, thermo kopel, tacho meter, stopwatch dan satu unit pengolah tepung pisang serta sealer.

\section{METODE}

Penelitian dilakukan dengan dua tahap, yaitu pengujian pendahuluan dan pengujian utama.Pengujian pendahuluan bertujuan untuk menguji kerja masing -masing alat secara keseluruhan. Sedangkan pengujian utama adalah pengujian unjuk kerja alat tiap - tiap bagian dengan cara menghitung kapasitas, rendemen, dan efisiensinya. Kapasitas alat diambil sample sebanyak 4 (empat) kali pengulangan, demikian pula untuk rendemen dan efisiensi alat sample diambil sebanyak empat kalipengulangan.

Tahapan proses pengolahan tepung pisang adalah sebagai berikut :

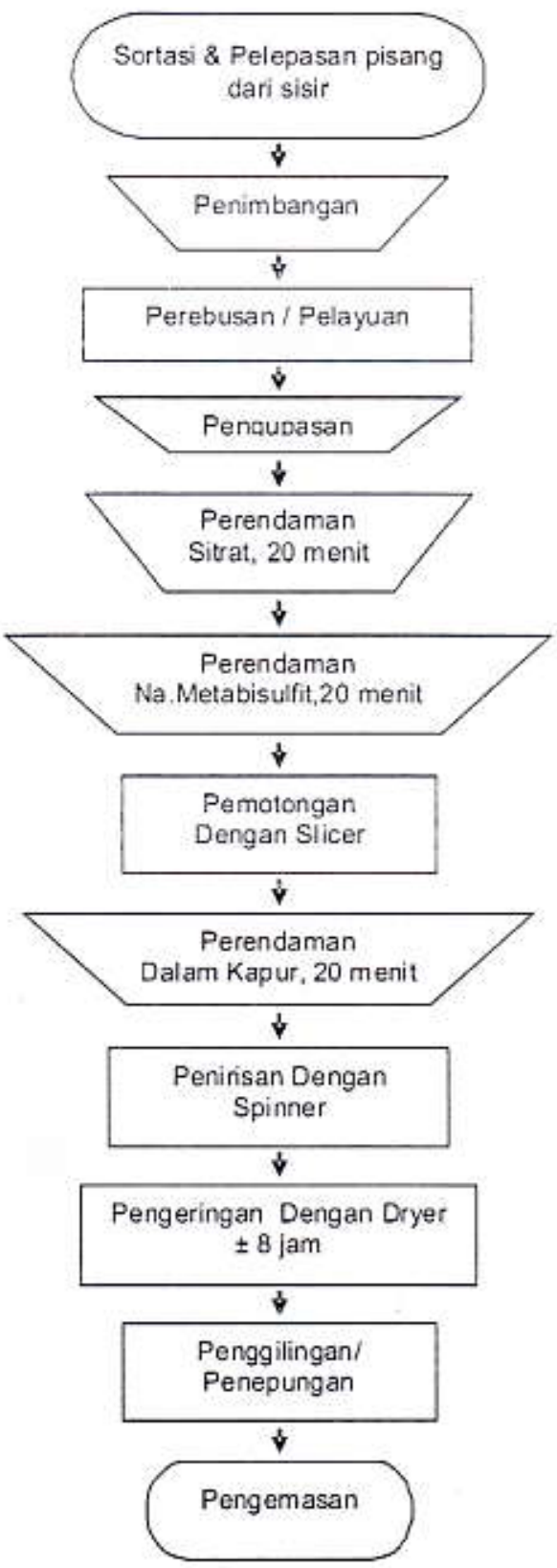

Gambar 1. Hroses Hengolanan lepung Pisang 
Sortasi bertujuan untuk mendapatkan bahan baku yang baik. Sortasi diperlukan untuk dapat menghasilkan mutu hasil yang baik dan seragam. Setelah sortasi dilakukan pelepasan dari sisir dan penimbangan, kemudian pisang direbus untuk menghilangkan getah dan memudahkan dalam pengupasan.

Sebelum dilakukan pemotongan pada slicer, pisang terlebih dahulu direndam dalam larutan sitrat dan natrium metabisulfit masing-masing selama 20 menit. Pemotongan dengan slicer memasukkan bahan secara manual, ditimbang bahan yang masuk dan dicatat waktu pemotongan serta perhitungan rpm sebelum dan sesudah mendapat beban dengan menggunakan tacho meter. Demikian pula hal yang sama dilakukan untuk alat yang lain seperti spinner, dryer, dan penepung (disk mills).

\section{HASIL DAN PEMBAHASAN}

\section{Pengujian Pendahuiuan (Pra Pengujian) \\ Unit Pelayuan Bahan}

Alat ini terbuat dari stainless steel berukuran $180 \times 80 \times 60 \mathrm{~cm}$ dan menggunakan pemanas kompor minyak tanah. Berfungsi untuk pelayuan bahan agar memudahkan pengupasan dan mengurangi getah. Untuk mengurangi getah perlu dicari metode pelayuan yang lebih efisien agar proses pengupasan lebih cepat dan agar perubahan warna diminimalkan. Untuk mengetahui berapa persen bagian daging buah pisang perkulit, diperlihatkan pada tabel 1 .

Tabel 1. Persentase berat buah pisang tanpa kulit terhadap buah pisang berkulit

\begin{tabular}{|c|c|c|c|}
\hline No & Dengan Kulit ( gr ) & Tanpa Kulit ( gr) & $\begin{array}{c}\text { Persentase } \\
(\%)\end{array}$ \\
\hline 1 & 2 & 1,5 & 75 \\
\hline 2 & 2,25 & 1,5 & 66 \\
\hline 3 & 1,50 & 1,25 & 83 \\
\hline \multicolumn{3}{|c|}{ Rata - rata } & 74 \\
\hline
\end{tabular}

Dari hasil pengamatan menunjukkan bahwa $74 \%$ buah pisang adalah daging buah pisang (diluar kulit ). Hal ini diperlukan untuk menginterprestasikan proses pengolahan selanjutnya.

\section{Unit Pengirisan ( Slicer)}

Alat ini terbuat dari bahan stainless steel diluar rangka dan as piringan. Digerakkan dengan motor penggerak 1/3 HP. Hasil pra pengujian menunjukkan banyaknya bahan tercecer akaibat belum terpasang penutup corong pengeluaran. Sering terjadinya kemacetan pengirisan akibat belum terampilnya operator dalam menangani pemasukan bahan ke lubang pemasukan yang menggunakan alat pendorong.

\section{Unit Peniris (Spinner)}

Alat ini terbuat dari bahan stainless steel adn perfo stainiess steel ukuran $75 \times 60 \times 50 \mathrm{~cm}$. Digerakkan dengan motor 1/3 HP. Bahan dimasukkan dalam keranjang peniris dan setelah selesai diangkat bersama keranjang dan dicurahkan ke loyang ( rak) penampungan. 


\section{Unit Pengering (Dryer)}

Alat ini berdinding plat esser dan plat mild steel rangka rak terbuat dari siku aluminium dan rak terbuat dari kasa aluminium. Pemanasan memakai sistem heat exchanger terbuat dari pipa simles. Unit pemanas memakai kompor minyak tanah ( brander ). Sedangkan pembawa aliran panas menggunakan blower tipe centrifugal. Suhu dikontrol dengan thermokopel (thermometer). Ukuran plat $244 \times 122 \times 122 \mathrm{~cm}$. Hasil pra pengujian menunjukkan bahwa bahan tanpa menggunakan kapur sirih warnanya kurang putih dan bergumpal-gumpal. Pengeringan yang dihentikan semalam akibatnya warna tepung kurang putih.

\section{Unit Penepung ( Disk Mill)}

Alat ini menggunakan elektro motor $5 \mathrm{HP}$. Alat ini harus menggunakan wadah penampung yang tertutup dan bisa menahan hembusan kipas agar hilang tercecer diminimalkan.

\section{Hasil Penelitian Utama ( Hasil Pengujian)}

\section{Unit Pengupasan}

Input bahan masuk yang akan diuji sejumlah $160 \mathrm{~kg}$ pisang mentah. Dilayukan dengan alat pelayuan selama 10 -15 menit dengan air panas, kemudian dikupas secara manual tenaga manusia menghasilkan buah pisang tanpa kulit seberat $118,4 \mathrm{~kg}$.

\section{Unit Pengirisan (Slicer)}

\section{Uji Kapasitas Pengiris Aktual}

Kapasitas aktual suatu alat atau mesin adalah kemampuan alat (mesin) untuk menghasilkan suatu produk per satuan waktu aktual.

Tabel 2. Rata - rata kapasitas pengiris aktual pengiris

\begin{tabular}{cc|c|c}
\hline No & Bs & Wpn & Kpn \\
\hline 1 & 2 & 43 & 167,44 \\
\hline 2 & 2 & 38 & 189,44 \\
\hline 3 & 2 & 41 & 175,61 \\
\hline 4 & 2 & 40 & 180,00 \\
\hline \multicolumn{3}{r|}{ Rada- rata } & 177,51 \\
\hline
\end{tabular}

Keterangan :

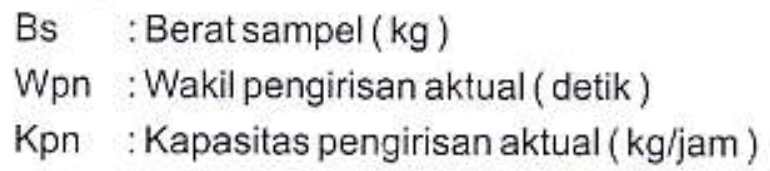

Dari tabel 2. terlihat kapasitas aktual diperoleh dari hasil bagi antara berat irisan aktual dan waktu aktual yang dipergunakan oleh alat pengiris. Hasil perhitungan menunjukkan kapasitas mesin sebesar $177,51 \mathrm{~kg} / \mathrm{jam}$. Kapasitas ini dipengaruhi oleh jumlah putaran piringan pengiris per menit. Jika jumlah putaran bertambah maka kapasitas mesin akan bertambah pula.

Ketebalan turut mempengaruhi kapasitas mesin, karena semakin tebal irisan senakin besar pula kapasitasnya. Untuk kapasitas yang disebut diatas adalah untuk ketebalan rata-rata 2,016 $\mathrm{mm}$.

Dari berat bahan yang masuk sebesar $118,4 \mathrm{~kg}$ seluruh hasil irisan ditampung dan alat 
penutup corong pengeluaran telah dipasang penutupnya juga yang tertinggal di dalam alat ditampung sehingga yang tercecer diabaikan/tidak ada.

\section{Kapasitas Pengirisan Teoritis}

Kapasitas pengirisan berdasarkan pendekatan teoritis diperoleh $655,52 \mathrm{~kg} / \mathrm{jam}$, pada luas effektif pengirisan $72 \mathrm{~cm} 2$, tinggi efektif pengirisan $0,20 \mathrm{~cm}$, rapat jenis pisang $0,98 \mathrm{gr} / \mathrm{cm} 3$ dan waktu pengirisan effektif 0,31 detik.

Luas efektif diperoleh dengan menghitung luas bagian dalam corong pemasukan, . Waktu pengirisan efektif diperoleh dari waktu yang digunakan satu kali putaran piringan pengirisan dimana diperoleh rata-rata kecepatan putaran $190 \mathrm{rpm}$.

\section{Effisiensi Kerja Alat Pengiris}

Effisiensi kerja alat adalah hasil bagi antara kapasitas pengiris aktual dan kapasitas pengiris teoritis.

Tabel 3. Rata-rata hasil perhitungan effisiensi kerja alat pengiris

\begin{tabular}{c|cc|cc}
\hline No & Bs & Kpn & Kpt & Eff (\%) \\
\hline 1 & 2 & 167,44 & 655,52 & 25,54 \\
\hline 2 & 2 & 189,47 & 655,52 & 28,90 \\
\hline 3 & 2 & 175,61 & 655,52 & 26,78 \\
\hline 4 & 2 & 180,00 & 655,52 & 27,46 \\
\hline \multicolumn{5}{c}{ Rata - rata } \\
\hline
\end{tabular}

Keterangan :

$$
\begin{aligned}
& \mathrm{Bs}=\text { Berat sample }(\mathrm{kg}) \\
& \mathrm{Kpn}=\text { Kapasitas pengirisan aktual }(\mathrm{kg} / \mathrm{jam}) \\
& \mathrm{Kpt}=\text { Kapasitas pengirisan teoritis }(\mathrm{kg} / \mathrm{jam})
\end{aligned}
$$

Dari tabel diatas, terlihat bahwa effisiensi kerja dipengaruhi oleh kapasitas pengirisan aktual. Semakin kecil kapasitas pengirisan actual semakin kecil effisiensi kerja alat. Untuk meningkatkan kapasitas aktual ini antara lain dengan memodifikasi sudut masuk corong pemasukkan agar bahan dapat masuk lebih cepat lagi akibat adanya gaya berat benda itu sendiri. Faktor yang lain adalah tingkat keterampilan operator juga merupakan penentu besarnya kapasitas aktual alat.

\section{Unit Penirisan (Spinner)}

\section{Kapasitas Penirisan}

Tabel 4. Kapasitas penirisan aktual

\begin{tabular}{c|c|cc|}
\hline No & $\begin{array}{c}\text { Berat sample } \\
(\mathrm{kg})\end{array}$ & $\begin{array}{c}\text { Lama penirisan } \\
\text { (menit) }\end{array}$ & $\begin{array}{c}\text { Kapasitas penirisan } \\
\text { (kg/menit) }\end{array}$ \\
\hline 1 & 6 & 2 & 3 \\
2 & 6 & 2 & 3 \\
\hline 4 & 5,5 & 2 & 2,75 \\
\hline & 3,5 & 2 & 1,75 \\
\hline
\end{tabular}


Lama penirisan ditentukan oleh habisnya air yang ditiriskan, oleh karena masih relatip maka berat sample yang maksimum untuk lama 2 menit perlu ditetapkan lagi.

\section{Rendemen Penirisan}

Perbandingan berat sesudah dan sebelum penirisan disebut rendemen penirisan.

Tabel 5. Rendemen penirisan

\begin{tabular}{|c|c|c|c|}
\hline No & $\begin{array}{c}\text { Berat awal sampel } \\
(\mathrm{kg})\end{array}$ & $\begin{array}{c}\text { Berat akhir sample } \\
(\mathrm{kg})\end{array}$ & $\begin{array}{c}\text { Rendemen } \\
(\%)\end{array}$ \\
\hline 1 & 6 & 4,8 & 80 \\
2 & 6 & 4,5 & 75 \\
\hline 2 & 5,5 & 4,2 & 76 \\
\hline 4 & 3,5 & 3 & 85 \\
\hline & \multicolumn{2}{|c|}{ Rata-rata $=$} & 79 \\
\hline
\end{tabular}

Bahan yang masuk $118,4 \mathrm{~kg}$ dan yang keluar $113,90 \mathrm{~kg}$, dimana yang hilang berupa $2,81 \%$ material dan sisanya berupa air yang ditiriskan.

\section{Unit Pengering (Dryer)}

Bahan yang masuk $113,90 \mathrm{~kg}$ dikeringkan selama 10 jam, sehingga kapasitas pengeringan sebesar $11,39 \%$. Rendemen pengeringan sebesar $24,84 \%$ dimana berat awal sample $16,5 \mathrm{~kg}$ dan setelah pengeringan $4,1 \mathrm{~kg}$. Ini berarti ada kehilangan hasil (losses) sebesar 50,22\% dari berat totalnya dimana $45,43 \%$ hilang berbetuk uap air dan $4,79 \%$ hilang berbentuk material selama proses pengeringan.

\section{Effisiensi Pengeringan}

Effisiensi pengeringan adalah perbandingan energi menguapkan air dari bahan dan energi yang dipakai dari sumber panas (kompor minyak tanah). Effisiensi pengeringan dihitung sebesar $20,49 \%$ dimana massa air yang diuapkan $72,68 \mathrm{~kg}$, panas laten penguapan (hfg) $2364,44 \mathrm{Kj} / \mathrm{kg}$, massa bahan bakar minyak tanah $19,5 \mathrm{~kg}$ dan panas pembakaran minyak tanah $42.990,02 \mathrm{Kj} / \mathrm{kg}$.

\section{Unit Penepung (Disk Mill)}

Rendemen penepungan $87,80 \%$, dimana bahan yang masuk $33,54 \mathrm{~kg}$ dan yang keluar $29,45 \mathrm{~kg}$. Ini berarti ada bahan yang hilang sebesar $2,56 \%$ dariberat total.

Total rendemen seluruh unit pengolahan sebesar $18,41 \%$, sedang total hilang/loss sebesar $81,59 \%$ yang terdiri dari $26 \%$ berupa kulit pisang, $10,16 \%$ berupa hilang tercecer dan $45,43 \%$ berupa uap air selama pengeringan.

\section{KESIMPULAN DAN SARAN \\ Kesimpulan}

1. Kapasitas Pengirisan aktual rata-rata sebesar $177 \mathrm{~kg} / \mathrm{jam}$ dengan ketebalan rata-rata $2 \mathrm{~mm}$. Effisiensi kerja alatpengiris $27,7 \%$.

2. Kapasitas Penirisan berkisar antara $1,75-3 \mathrm{~kg} /$ menit atau rata-rata $2,52 \mathrm{~kg} /$ menit. Rendemen rata-rata $79 \%$ dan hilang tercecer $2,81 \%$.

3. Kapasitas pengering $11,39 \mathrm{~kg} / \mathrm{jam}$ dengan rendemen $24,84 \%$ serta hilang tercecer $4,79 \%$. Effisiensi pengering dengan sistem heat exchanger sebesar $20,49 \%$.

4. Rendemen Penepung $87,80 \%$ dan hilang tercecer $2,56 \%$. 


\section{Saran}

1. Pada penelitian lanjutan perlu diteliti corong pemasukan alat pengiris (slicer) perlu dihitung sudut maksimum.

2. Agar kapasitas pengering diperbesar atau lama pengering dipersingkat pergantian rak dirobah dengan langsung mendorong rak kedepan arah ke sumber panas (counter flow) bila rak di depan sudah dikeluarkan.

3. Perlu diteliti sistem tata letak unit pengolahan yang effisien,

\section{DAFTAR PUSTAKA}

AntoniAhmad,1995. Kamus Lengkap Teknik. Gitamedia Press. Surabaya

Anonim, 2001. Propil Industri Kecil Keripik Buah. Proyek Pengembangan Dan Pelayanan Teknologi Industri Kalimantan Timur

Anonim, 2001. Propil Industri Kecil Tepung Pisang. Proyek Pengembangan Dan Pelayanan Teknologi Industri Kalimantan Timur

Sutanto. 1983. Himpunan Satuan Dan Konversinya. Bhrata KaryaAksara. Jakarta

Tosin Rijanto. 1994. Flow Chart untuk Siswa dan Mahasiswa. Dinastindo. Jakarta 